\title{
Ussi ja siksaki motiivid soome kaljumaalingutes ja saami trummidel
}

\author{
$\underline{\text { Eero Autio }}$
}

Soome kaljumaalinguid käsitlevates artiklites on erilist tähelepanu pööratud shamanismile (nt Siikala 1980; Miettinen 1982). Selline rõhuasetus viib järelduseni, et mehe ja ussi või ussitaolise siksaki motiiviga kompositsioonil kujutati shamaani ja teda abistavat looma.

Selline seletus põhineb traditsioonilisel arktilise shamanismi kontseptsioonil, mida toetab Skanke-Jesseni avastus, et sama motiiv esineb saami trummidel. Olen mitmel puhul leidnud, et eelkõige shamanismil rajanev tõlgendus ei anna usaldusväärseid tulemusi piktograafide (kaljumaalingute) ja petroglüüfide (kaljujooniste) uurimises. Segadusse ajav on ka ussi või siksaki asukoht Åsele-tüüpi trummidel. Erinevalt Bo Sommarströmist pole ma veendunud, et see on seostatav Skandinaavia Nidhöggr'iga (Sommarström 1987: 223). Soome kaljumaalingutel leidub ussi või siksaki kujutist ainult Sarakallio Laukaas (Kesk-Soomes), Juusjärvi kaljumaalingutel Kirkkonummis (Helsinki lähedal), Kolmiköytinenis Ruokolahtis (Saimaa järve idakaldal), Mertakallios Iittis (Lõuna-Soomes) ja Haukkavuoris (IdaSoomes).

Üks Sarakallio ussikujutis on väga sarnane mingile sisalikule (joonis 1a). Peaaegu samasuguse joonise leiame ka Karjala petroglüüfide hulgast (joonis 1b). Mõlemad kujutised näivad kuuluvat fallosekultusse, mis oli eriti populaarne pronksiajal. Kui oletamisi siduda omavahel ussi ja falloselist joonistust Sarakallios, siis leiame sellele kompositsioonile vaste vanast kelti maailmast (joonis 1c). Arvatakse,

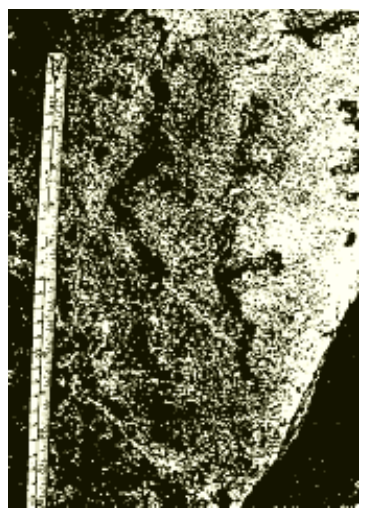
et pildil kujutatud mees esindab mõnd jumalat, kõige tõenäolisemalt Cernunnost, kuna seda jumalat kujutati koos ussiga Val Camonica petroglüüfidel (MacCana 1983: 39, 42).

Teisel Sarakalliost pärit siksaki motiivil (joonis 1d) paiknevad siksaki all kaks paati ja paremal üksteise taga seisvad inimkujud. Uurides Sarakallio inimkujusid oli mu esimene mõte, et peaaegu samasugust 'tegevust' leidub Karjala kaljujoonistel, eriti Uikujoe suudmes (joonis 1e). Karjala 'stseen' on nii elavalt kujutatud, et igaüks mõistab, mis pildil toimub. Selline maagiline inimeste paaritumiseviis kuulus viljakuskultuse juurde (Autio 1981: 89). Sellele osutavad ka loomamaskid.

Otse paatide all on kaks inimkuju, kes otsekui hoiaksid paate üleval. Peaaegu samasugust kompositsiooni võib leida Skandinaavia petroglüüfidel (joonis 1f). Arheoloog Göran Burenhult on Egiptuse surnutele pühendatud paatidele ja eelkõige Taani eelajaloolistele leidudele viidates tõestanud (joonis $1 \mathrm{~g}$ ), et nn 'paadikandja' motiiv on seostatav viljakusjumalannale määratud pühendusohvriga (Burenhult 1979: $17 \mathrm{jj}$ ). Mulle tundub, et Laukaa kompositsioon kujutab endast samuti pühendusohvrit. Manker kirjeldab, et saamidel oli komme teha kasekoorest paat, kallata sinna rasva ja riputada selline ohvripaat puu otsa jõulude ajal ringiliikuvatele vaimudele (Manker 1950: 57).

Arvatavasti olid need «ringiliikuvad vaimud» surnute hinged, keda usuti elavate maailma tulevat vana ja uue aasta vahel. See kristluse-eelne uskumus oli levinud Euroopas (James 1959: 149 jj, $316 \mathrm{jj}$ ), kuid seda tundsid ka soome-ugri rahvad, kes kostitasid oma esivanemaid ja surnud sugulasi kombekohaselt (Waronen 1895: 110 jj, 115, 118 jj; Holmberg 1914: 41 jj, 51).

Sarakallio kaljumaalingutel on kujutatud kaht inimest, selle Rootsi analoogil ainult ühte. Oletatavasti kujutatakse Sarakallio joonisel meest ja naist. Oula Näkkäläjärvilt ja Iisko 
Saralt 20. 08. 1988. aastal Turu linnas kuuldud seletuse kohaselt on isa ja ema pere ja nende esivanemad saamidel võrdse tähtsusega. See seletab kahe paadi olemasolu kompositsioonis: üks kuulub mehe esivanematele ja teine naise omadele. Tuletagem siinkohal meelde, et erinevalt indoeuroopa keeltest ei eristata soome-ugri keeltes mees- ja naissugu.

Sarakallio siksaki motiivi võib seostada ka esivanemate ja viljakuse kultusega. Minevikus polnud need kaks sfääri eraldiseisvad, nagu on näha etruski hauamaalingutest (joonis $1 \mathrm{~h}$ ). Viljakuse ja esivanemate kultust oli põimunud näiteks sellisel vanal kalendritähtpäeval nagu Ida-Soome kekri. Selliste traditsioonide taga tundub olevat uskumus, mille kohaselt esivanemad nagu ka jumalad võisid aidata oma järeltulijaid (vt näiteks hantidel Holmberg 1914: 51 jj). Oula Näkkäläjärvi ja Iisko Sara andmeil kasutati esivanemaid puudutavaid termineid lineaarses järgnevuses. Kolmanda ja veel vanemate generatsioonide kohta kasutati sõna mattar áhkku (emapoolsed) ja mattar áddja (isapoolsed). Mõlemat sõna võib nende sõnutsi seostada jumalatega. See on nii kõigis saami murretes (Ränk 1949: 189).

Oma tähendus võib olla ka sellel, et siksak on kompositsioonides mitte vertikaalne, vaid horisontaalne. Võibolla on märkimist vääriv, et lookeid on seitse. Sama arv esineb ka Uurali vastavatel joonistel.

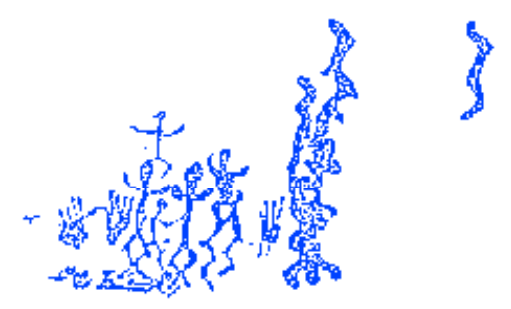

Juusjärvi kaljumaalingutel (joonis 2) paiknevad ussilaadsed kujutised paremal. Kahtlemata on kujutised omavahel tähenduslikult seotud. Shamanismil põhinev seletus tundub võimalik, eriti kuna üks inimkujutis tundub olevat ussi ja inimese hübriid. Kahe käe kujutis vasakul, kui nad sümboliseerivad käte või koha vaimu (Siikala 1980: 186), toetab shamanistlikku seletust.

Kaks kätt kokkupuutuvate pöialdega võib muidugi tähendada erinevaid asju: võmalik, et iidne joonistaja tahtis kujutada arvu kümme, millel oli vanasti suur tähtsus. B. A. Frolov on uurinud numbrite esinemissagedust paleoliitses kunstis ning seda, miks teatud numbreid kasutati sagedamini kui teisi. Tema järeldab, et kümne sagedus on seletatav sõrmede arvu ja raseduse kestusega, mis vältab kümme lunaarkuud (Frolov 1974: $131 \mathrm{jj})$.

Kümmet võib leida ka soome kammkeraamilistel nõudel. Kuigi vähesed rekonstruktsioonid pole piisav tõendusmaterjal, kutsuvad nad meid arvestama ka teisi võimalusi peale shamanismi. Ma nõustun arheoloog Ville Luhoga, kelle sõnade kohaselt võivad Juusjärvi maalingud olla mingil moel seotud viljakusmaagiaga (Luho 1962: 71).

Kolmiköytineni maalingutel on ussi kujutised ja peaegu samasugune hübriid kui Juusjärvis (joonis 3a). Timo Miettinen (TY Miettinen 1987) on arvanud, et Kolmiköytineni hübriid kujutab shamaani teel teise ilma. Pika jalaga kuju leidub ka Nämforseni petroglüüfidel (Hallström 1960: 349), Karjalas ja Tomi jõel Lääne-Siberis (joonis 3b). A. P.

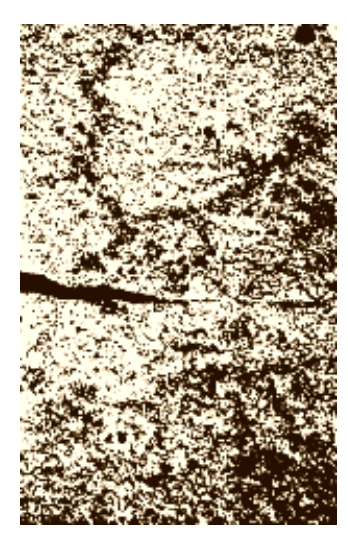
Okladnikovi, tuntud kaljukunsti-eks-
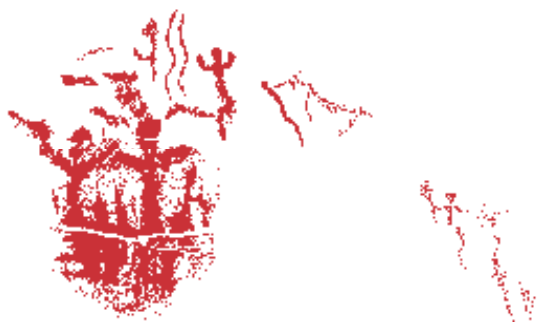
perdi arvates võib selliseid kujutisi seostada mõne vaimuolendiga (Okladnikov \& Martõnov 1972: 210). Kuna suured inimkujud Kolmiköytinenis justkui tantsiksid, rõhutab see jooniste rituaalset olemust, nende seostamine shamanismiga tundub igati võimalik. Põdra lähedal paikneval ussikujutisel on vaste Siberi petroglüüfides. Okladnikovi arvamuse kohaselt kuulub see kombinatsioon viljakuskultusesse (Okladnikov 1966: 118).

Mertakallio kaljumaalingutel (joonis 4a) võib näha siksaki ja inimese kujutist. Nende all, kuigi väga ebaselgelt, on veel üks inimene. Umbes 1,5 $m$ suurusel pildil on joonistuse kohal põdra kujutis. Inimese ja ussi kombi- 
natsiooni näeme ka Haukkavuoris (joonis 4b). Timo Miettinen seletab seda shamanismiga, kuid viitab ka seosele jahimaagia ja viljakuskultusega. Tema oma sõnade kohaselt oli viimane ... sügavalt mõistetud, kõige taga (Miettinen 1982: 11).

Parema ülevaate saamiseks tuleks siinjuures arvestada vähemalt Skandinaavia, Karjala ja Uurali kaljujooniseid. Skandinaavias oli see motiiv laialt levinud, eriti pronksiajal ning sel on selge seos viljakuse kultusega (joonis $\underline{5 \mathrm{a}}, \underline{5 \mathrm{~b}} ; \underline{\mathrm{g}}$ ). Kõige huvitavam, kuid raskeim tõlgendada (Hallström 1960: 17) on jooniste grupp Hästskotsjärnist (joonis 5c). Esmapilgul näib jooniste kombinatsioon olevat väga shamanistlik: üks uss on koguni mehe peakatte peal. Kuid mulle tundub see mees pigem rõõmsa või lõbusana kui hirmununa. Puusad, neist väljuvad kiirtetaolised jooned ja üks petroglüüf Alta fjordis, Kvinne som sitter pa et reinsdyr (joonis 5d) kallutavad mind arvama, et Hästskotsjärni petroglüüf on müütilise taustaga ja seotud viljakuskultusega.

Ussimotiivi leidub ka Alta kaljujoonistel (joonis 5e). Knut Helskogi arvates võib inimese kujutis tähistada müütilist olendit või transis shamaani (Helskog 1988: 110). Viimast seletust toetavad mõned Siberi petroglüüfid (nt joonis $5 \mathrm{f}$ ), mida on tõlgendatud shamaanina (Okladnikov 1966: 137). Kuid Altas, isegi sama kalju peal, leidub inimese kujutis, mille sisse on pandud teine inimese kujutis või põhjapõder või midagi muud (Helskog 1988: 66 jj). Viimase asjaolu tõt-

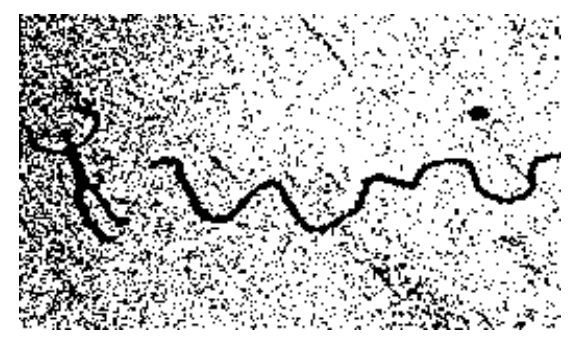
tu, aga ka kahe põhjapõdra pärast, kes näivad kompositsooni kuuluvat, arvan ma, et seletus mü̈̈tilisest olendist on usutavam kui shamaan.

Uss on äärmiselt selgelt kujutatud nii Karjala Uikujoki kui Äänisjärve (Onega) idakalda petroglüüfidel. Vana-Zalavruga petroglüüfide peagrupis (joonis 6a) asub üks uss keskel seisvast atleetlikust mehest vasakul. Meest on tõlgendatud kui suurt shamaani või mõnda jahimeestele soodsat jumalust (Linevski 1939: 179; Raudonikas 1936-38: 2, 48).

Pildi all paremalt kuuenda põhjapõdra tagajala juures asub veel üks uss. See ebaharilik kombinatsioon toob mulle meelde ingeri runolaulu Põder ja uss (Autio 1984). Motiiv oli populaarne keskaegses Euroopas, kuid pärineb veel vanemast ajast. Selle motiivi kohaselt tapab põder ussi; ingeri värssides põder ainult lööb ussi jalaga ribidesse. Sellal kui uss on

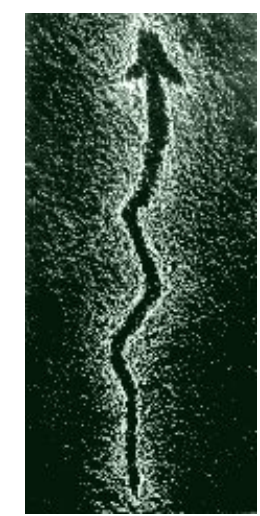
külili ja oigab, tuleb Margareeta ema ja lüpsab teda. Piima kukub maha, mispeale puud ja loodus puhkevad oitsele. Ma oletan, et nende jaoks, kes Zalavruga joonised tegid, oli ussil mingi positiivne tähendus. Sama võib oletada ussikujutiste kohta Zalavruga lõunapoolsel grupil (joonis 6b), kuigi mees pildil tundub usse eemale tõrjuvat. Ühel Karjalas Äänisjärve ääres (joonis 6c) paikneval petroglüüfil on ussi käänukohtadel lühikesed jooned ehk ripatsid. Selliseid näeme ka Juusjärvi kaljumaalingu ussi juures (joonis 2) ja Uuralides (joonis $\underline{7 a}, \underline{7 b}$ ).

Sellised siksak-motiivid on iseloomulikud Uurali kaljujoonistele. V. N. Tshernetsov, arheoloog ja lingvist, leidis taolistele motiividele vasteid obiugrilaste ehetes, pronksiaja keraamika kaunistustes ja Shigirskist leitud neoliiti0kumi mõõgapealt (Tshernetsov 1971: 37, 107 jj). Tavaliselt tõlgendab ta selliseid siksak-motiive (joonised $\underline{7 b}$ ja $\underline{7 c}$ ) kui püünisaedu (Tshernetsov 1964: 24; Tshernetsov 1971: 64 jj). See tõlgendus on küsitav, vähemalt käesolevail juhtudel.

Lihtsalt uss (joonis $7 \mathrm{~d}$ ) on Uuralides haruldane. Tshernetsovi arvates kujutab kogu grupp veelindude püüdmist (Tshernetsov 1964: 39 jj). Ussi asukoht paneb mind selles

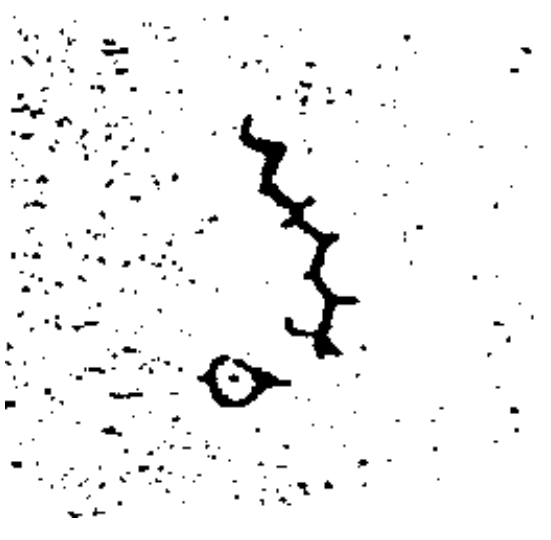


tõlgenduses kahtlema. Ussimotiiv ilmub Uuralidesse juba paleoliitikumis (joonis 7e). Okladnikov ja Petrin on ussil loendanud seitse maagilist looget (Okladnikov \& Petrin 1983: 54). On märkimist vääriv, et sama arv esineb väga tihti hilisemates Uurali joonistes ja ka Soomes (joonis $\underline{7 a}$ ja $\underline{7 \mathrm{c}}$ ).

Uuralide ja kaugema materjaliga võrdlemine on oluline, kuna ida poole peame me vaatama otsides jahimeeste ja kalurite kultuure (Gjessing 1978: 21; Aspelin 1877). Tshernetsov on tõestanud, et Uuralide kaljujooniseid tegid hantide-manside esivanemad. Iidne kammkeraamika kultuur oma eri variantides ulatus Lääne-Siberist Põhja-Skandinaaviani ning tolleaegsed kaubanduslikud sidemed pole sugugi tähtsusetud, nagu tõestab näiteks Siberi männist valmistatud lusika leid Laukaas.

Uurali maailmal oli arvatavasti suur tähendus ka saami trummide jaoks. Sarnasused saami ja obi-ugri keelte vahel, matriarhaalsed jooned nende jumaluste juures ning muud sarnasused religioonis, mida täheldasid juba Gustav Ränk ja teised uurijad, toetavad seda järeldust. Pole juhuslik, et solaarsel sümbolismil on keskne roll nii saami trummidel kui Uurali (ja ka Siberi) kaljutaides. Samuti võib obi-ugri kolme maailma mudelit (allilm, keskmine ilm ja ülailm) leida saami trummidel.

$*$

Saami trumme võib jagada neiks, milles Päivö sümbol, päike koos ohjadega (labikie) on trumminaha keskel, ja neiks, mille illustreeritud pind on jagatud kaheks või rohkemaks osaks. Esimest ehk nn Åsele-tüüpi, peetakse teistest vanemaks. Seetõttu olgugi keskendutud sellele kui kaljujooniste tõlgendamiseks sobivamale. Pildid ja trumme puudutavad väited pärinevad enamasti Mankeri raamatust Die Lappische Zaubertrommel I-II (Manker 1938; Manker 1950), aga ka muudest allikatest.

Ussi või siksaki kujutis esineb 30 Åsele-trummil ja asub Päivö sümbolist vasakul (tab 1A). On ainult kaks erandit. Trummil 36 (identifitseerimata siksak) on see paremal üleval, kõrgeima jumala Radien attje kujutise kõrval, puu on arvatavasti kasvu sümbol. 32. trummil asub see motiiv päikese sümboli all, kuid küllalt lähedal selle kiirtele (joonis 8d).

Ussi või siksaki kujutist ümbritsevate motiivide arv on ära toodud tabe-lis 1B. Kõige arvukam on saami küla või saami hütt (kota) (17-2 st kokku 17 trummil, neist kahe puhul on tõlgendus ebakindel). Järgnevad ohverduskoht (16), ohvriloom (13-1), põhjapõder/põhjapõdra kari/põhjapõdra aedik (10), mees/suusataja/kalastaja (8-1), ait (6), kalavõrk/kalapaat või järv (9-4). Kategooria 'mingi jumalus' alla mahub erinevaid jumalusi: neist neli kujutab ilmselt Ailekesolmaksit ja üks on arvatavasti mingi jumal või shamaan.

Viimatimainitu on trummil 19 kujutis 57 (joonis 8e). Kuna kujutisi 13 ja 12 samal trummil seletatakse kui 'shamaani ja trummi', siis peaks kujutis 57 olema pigem jumal kui shamaan. Identifikatsiooni 'shamaan ja/või trumm' on kasutatud kuuel korral, kuid kolm neist on kaheldavad.

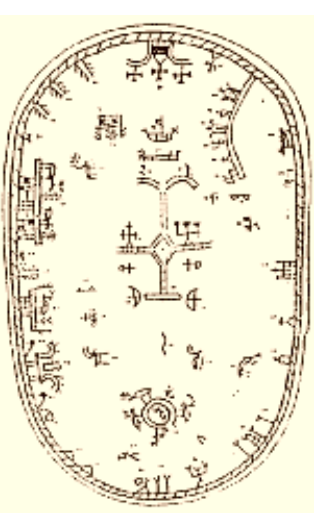
Shamaani põhjapõtra (noiade sarva) või mõnda muud shamaani looma leidub 8-1 juhul (tab 1B).

Allilma / teist ilma on tõlgendustes mainitud kolme trummi puhul, need on aga kaheldavad tõlgendused. Manker arvab, et trummil 11 on 4-nurgeline kuju ehk päikese ohjad (labikie), mis osutab allapoole. Trummil 12 on käändude ja joonte poolt moodustatud kujutis niivõrd unikaalne, et tõlgendamisel pole teistel trummidel leiduvatest märkidest üldse abi. Ka kujutise asukoht on allilma jaoks ebaharilik.

Karu ja kopra motiividel oli ka müütiline tähendus. Enamikule motiividele ussi või siksaki lähedal on tunnuslik, et nad on seotud saamide igapäevase elu ja materiaalse eksistentsiga. 
Sama kehtib ka Horgallesi (Tiermes) ohvriloomade märgi kohta, kuna see jumal oli vanim, austatud, teda peeti põhjapõtrade kaitsjaks (Andelin 1858: 242 jj).

Mõned tõlgendajad on viidanud ussile sõnadega noiade kärmai (shamaani uss) või guolle (kala), kuid enamasti on kasutatud ainult sõna uss. Mõned informandid peavad ussi vastikustäratavaks olevuseks ning pole põhjust selles väites kahelda. Ussi suhtuti Lapimaal vaenulikult, nii et tapeti nii süütuid sisalikke kui usse, väidab T. I. Itkonen (Itkonen 1948: 373). Seejuures ei tohi unustada, et kõik kommentaarid usside kohta pärinevad kahest viimasest sajandist ning on seega suhteliselt hilised.

Åsele trummide ussikujutiste omadusi saame hinnata tabelite 1A ja 1B abil. Åsele trummidel on uss teise ehk allilma, Saivo-, Jabme- ehk Rota-aimo vastas, mille kujutised asuvad päikese sümbolist paremal. Ainus erand on trumm 36, mis tundub isegi reeglit kinnitavat, aga seda muidugi juhul, kui puu märk on tõesti kasvu sümbol (Wachstumsymbol) ning siksak tähistab ussi.

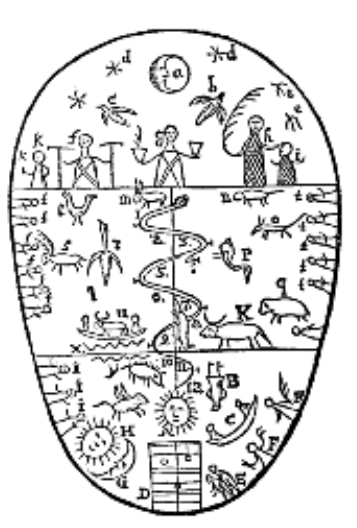

Anders Andelin pakub oma artiklis «Kertomus Utsjoen pitäjästä» ussi asukoha tõlgendamiseks trumminahal järgmise seletuse. Saamid uskunud, et koitu põhjustas Radien ning õhtuhämarust Rota ning et hämariku märk maaliti Rota-aimo kujutise lähedale (Andelin 1858: 264). See info läheb hästi kokku Freesi II trummiga (joonis 8c), kus on hommikuvalguse märk (joonis 3) Radieni grupis ja loojanguvalguse märk (47) paremal pool küllalt Rota-aimo lähedal. Ühel teisel trummil, Rudbecki L (joonis 9), on $k$-tähega tähistatud ülal vasakul asuvat kujutist peetud 'teenriks' (Diener), kelle ülesandeks oli üles riputada hommikutäht. Teistel trummidel, nagu näiteks 43:17 ja 64:5, pole need tõlgendused nii usaldusväärsed.

Andelini, Freesi ja Rudbecki informatsioon sundis mind uurima trummi sellisest posit-sioonist, et trummipea ülemine pool oli louna suunas. Siis osutas trummi parem pool päike-seloojaku poole ning teise ilma ja allilma märgid jäid siis lääne suunda.

Selline tõlgendus pole vastuolus uskumusega, mille kohaselt allilm on sõna otses mõttes maa-alune koht. Petroglüüfidel võib põdrapeaga paate või mõnda muud päikesesümbolit paadininas tõlgendada Osirise päikesepaadi ning sellega seotud uskumuste kaudu. Päikesepaadid Kaukasuse, Skandinaavia ja Siberi kaljujoonistel (nt Formozov 1966: 45) osutavad, et iidsed inimesed vajasid selgitust päikese igapäevase teekonna kohta. Kui päike loojus läände ja tõusis idast, pidi ta läänest itta minema läbi maa-aluse ruumi, mida kujutleti kui merd. Seepärast võis ka teine ilm olla läänes ja selle maailma all.

Mõned paadikujutised saami trummidel võivad olla selle uskumuse reliktid. Sellele viitab Skandinaavia sõna Ringhorna, mida kasutas Rudbeck. Põhjapõdra ja tema sarvede kujutis päikesesümboli sees võib olla veel üks jäänuk minevikust. Kui sees asuv kujutis tähendab

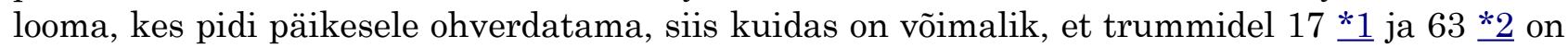
sama koha peal inimolendi pilt? Me võime tõlgendada nii inimese kui põhjapõdra kujutisi kui personifitseeritud päikese kujutisi. Kujutist võib seostada ka kolta-saami Meandash-põõrre, müütilise põhjapõdraga, kelle sarved särasid nagu päike (Tsharnoluski 1965: 74, 80; Okladnikov \& Martõnov 1972: 227).

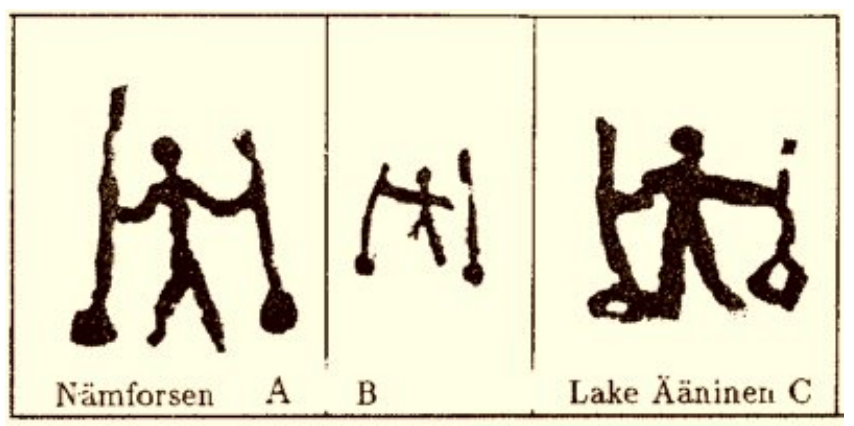


Need pole ainsad iidsed kujutised trummipealsetes piltides. Võib-olla kõige märkimisväärsemat sarnasust võib leida kujutiste kombinatsioonis, kus jumal hoiab labidataolisi objekte, mis asuvad tema kahel küljel (joonis 10a). Sarnane skeem $x A x$ on $n n$ 'teibakandja' kompositsioonis Onega ja Nämforseni petroglüüfidel (joonis 10b). Sarnast ikonograafilist skeemi leidub ka mõnedel obi-ugri hõbetaldrikutel, ent seal on meeste käes mõõgad (Spitsõn 1906, joonis $\underline{5}$ ja $\underline{7}$ ). Sama skeem on äratuntav ka kuulsas Kreeta ussijumalanna ikonograafias.
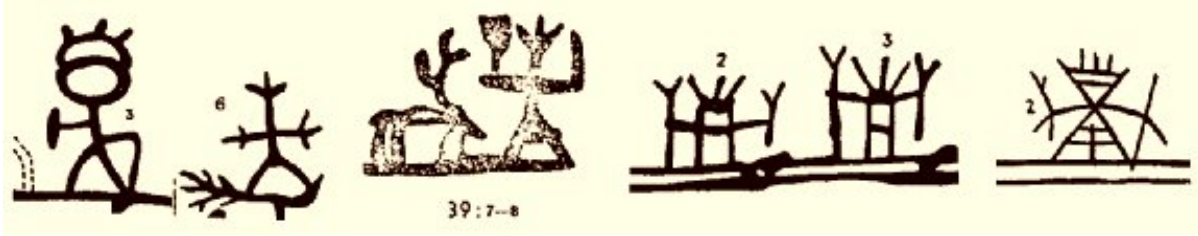

Neljas arhailine joon väljendub jumalate kujudes, kellel on kolm sarve või vertikaalne joon pea asemel (joonis 11a-f). Peaaegu samasuguseid kujutisi võib leida Alta kaljupiltidel Koola poolsaarel, Hossas Soomes, Uuralides ja Siberis, kuid mitte Lõuna-Skandinaavias (joonis 11gk). Motiivi esineb ka Permi pronkstöödes, obi-ugri taldrikutel, Lääne-Siberi pronksi-aegses kultuuris ja burjaatidel (joonis $11 l-p$ ).

Analoogiad trummil kujutatu ja petroglüüfide vahel toetavad täiendavalt järeldust, et saamide teine ilm asus varem läänes. Siit järeldub, et ida ei olnud õnnetu või kuri suund, nagu see tundub olevat Edda-maailmas (Tynni 1980: 12). Ussi asetsemine tõusva päikese suunas tähendas ilmselt midagi head.

Kaks ussi skulptuuri (joonis 12), mis leiti hauast Äänise piirkonnast ja pärinevad mesoliitikumi lõpust, osutavad, et nendega seotud uskumused olid positiivse tähendusega. Leinavad sugulased ei pane hauda midagi ebameeldivat. Sel

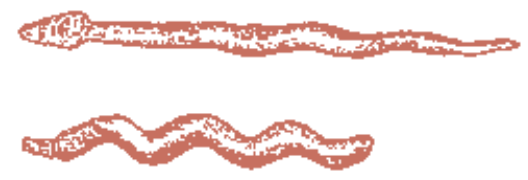
põhjusel ja tänu Skandinaavia petroglüüfides ja Taani pühendusohvris ussile omistatud tähendusele, jätan ma kõrvale kristlusest mõjustatud uskumused nagu ka Skandinaavia mao, Nidhoggri.

Iidses Egiptuses oli loomise sümbol Ürgmadu, kõige iidsem, kes hoidis kogu järgnevat loomist maailma algul oma loogetes. Kirstutekstides olid jumalate sõnad kuulutatud mao suu läbi (Clark 1960: 51jj, 75, 95, 106 jj).

Üks enimtuntud Kreeta jumalusi oli ussijumalanna. Ühes Knossose majas leiti väikesed tassid, mida kasutati vist ainult ussi toitmiseks, ja teda austati kui majavaimu kehastust. Uss oli ka allilma ja viljakuse sümbol ning tal oli sama funktsioon Mükeenes (James 1959: 129 jj). Pallas-Athena ussiembleem sümboliseeris vegetatiivseid jõude ja ka jumalanna kaitsjakohustust (Levy 1946: 331). Muistsetel keltidel oli ligilähedane uskumus: nende ikonograafias tähistas uss viljakust ja Bridgedi tunnusena oli selle funktsiooniks kurjade jõudude eemalhoidmine (nt Cooper 1983).

Soome rahvaluules tundub ussil olevat allilma valvuri, aga ka teatetooja roll, nagu näiteks runolaulus Päike ja kuu (Finnish folk poetry 1977, laul 31). Ussi hoiti lehmalaudas, rahvausundis oli sarve või krooniga uss hea õnne ja rikkuse kuulutaja (Ruuttu 1929; Haavio 1939: 46 jj). Sarnased uskumused olid levinud ka Eestis. Ühe Viljandi informandi sõnutsi tõi uss jõukust ja viljakust ning aitas säilitada sidemeid esivanematega (Meri 1983: 125).

Kaheks või rohkemaks osaks jagatud pealsega trummidel esineb ussi või siksaki kujutis 13 korral (tabel 2). Tavaliselt asub see allpoolses või alumises osas ning sel on selge side allilma või teise ilmaga (Jabme- või Rota-aimo) või Orre merega, kohaga, kus usuti päikest ja kuud talvel asuvat. 
Trummidel 61 ja 70 asub uss kuu kujutise lähedal. Frolovi järgi võib seda kombinatsiooni näha eelajaloolises materjalis kuni pronksiajani (Frolov 1974: 125). Ussi võimet nahka ära heita on seostatud kuu faasidega, selle surma ja uuestisünniga ning ka uuenemise ideega.

Asukoha poolest küllaltki huvitav ussikujutis leidub trummil 69 ja eriti trummidel Rudbeck K ja L. Neil asub uss trummi keskjoonel (trumm L, joonis 9). Rudbecki kohaselt sümboliseerivad ussi kolm alumist käändu (12-10) aasta pimedaimat aega ja pealmised (9-1) teisi kuid. Idee, et uss oli seotud ajaarvamisega, pole täiesti võimatu. Vähemalt oli tal küllalt väljapaistev koht sodiaagi vanimate märkide seas (joonis 13).

Trummil L on veel üks ussikujutis nagu ka Rudbecki trummil K. Need on väikesed ripatsid ussi ja siksaki käändudel. Kuigi nad ei ole päris samased petroglüüfi kujutistega (joonis $\underline{2}$, $\underline{6 \mathrm{c}}$ ja $\underline{7 \mathrm{a}}$ ), võivad nad aidata meil mõista veel ühte käsitletavate kujutiste funktsiooni petroglüüfide ajastul.

Ussi ja siksaki motiivi kasutati mõnede trummide puust kausikujuliste raamide ilustamiseks $(17,51,55,59-63,67$ ja 71). Ühel neist () näib siksakiline nikerdus «kausi» keskosale ringi peale tegevat. Märkimisväärne on, et sedalaadi kaunistusi ei leidu puhast Åsele-tüüpi trummidel. Motiivi kasutati vahel ka trumminuiade kaunistamisel.

Mõned informandid on nimetanud ringi või ringide kogumit (vuorra, arpa - 'palju') ussiks või konnaks. Tegemist võib olla reliktidega, kuna nende objektide kujus pole midagi, mis ussi või konna meenutaks.

$*$

Nagu ma sissejuhatuses märkisin, on Soome kaljumaalingute tõlgendamisel peamiseks probleemiks shamanismi osakaal. Peale 'kõige shamanistlikumate' motiivide jälgimist kaljutaides ja saami trummidel julgen teha vähemalt järgmisi üldistusi:

1) Peale shamanismi on muidki tõlgendamise võimalusi. Pühendusohver (votive offer) Sarakallio kompositsioonis osutab piisava selgusega, et iidsetel küttidel oli mõjutusi ka lõunast. Okladnikov ja Formozov on osutanud, et ideed võivad rännata lõunast põhja sama kergesti kui siberi mänd Soome (Okladnikov \& Martõnov 1972: 237-42; Formozov 1966: 124 jj; Formozov 1987: 40 jj). Veelgi enam, kompositsioonil, kus inimesed paarituvad loomade kombel, on vaste lõunas, mitte Siberis ega Uuralites.

2) Kopulatsioonistseen ja pühendusohverdamine Sarakallios näitavad selgelt, et iidne inimene ei lootnud mitte shamaani, vaid maagia ja viljakus- ning esivanemate kultuse peale. Põdraluude hulk kammkeraamika kultuuris näitab, et jahimehed oli väga osavad saagi püüdmises. Nende suurim probleem tundus olevat loomade arvukus ning see selgitab vajadust viljakusmaagia järele.

3) See kõik seab minu jaoks kahtluse alla kas kompositsioone, kus on koos inimene ja uss, on võimalik seletada vaid shamanismist lähtudes. Kui iidsel jahimehel oli erinevaid inimesetaolisi jumalaid ja müütilisi olendeid, pidi ta neid tähistama ussi, sarvede jms (vt ka Formozov 1987: 92-6). Ainult inimese ja ussi hübriidid Juusjärvis ja Kolmiköytinenis näivad viitavat shamanismile. On aga võimalik, et sealgi kujutatakse mingit meile tundmatut vaimolendit. Kompositsioonides, kus muud kujutised ussi või siksaki lähedal viitavad viljakus- või esivanemate kultusele, kuulub uss arvatavasti nendega samasse uskumuste kompleksi. Põdra ja ussi kujutiste koosesinemine viitab tõenäoliselt maagiale või viljakuskultusele.

4) Saami trummide ussimotiivide kohta väidetavat ei saa kaljumaalingutele otseselt üle kanda. Åsele-tüüpi trummidel näib ussi ja siksaki motiivi asukoht ning nende lähedal asuvate 
kujutiste oma järgivat mingit vanemat traditsiooni. Seda näitab ussi asukoht trummi vasakul poolel, mis on vaadeldav kui tõusva päikese suund. Lapi küla, ohvrikoha jms kujutised ussi lähedal toetavad ideed, et ussi varasem tähendus oli mingil moel positiivne ning et see oli seotud küllusega. Trummil on ka teisi kujutisi, mis tunduvad olevat mineviku reliktid. Neist kõige vaieldamatumaid on jumala kujutis, mille mõlemal küljel on labida-taolised märgid ning kolme sarvega jumalad.

5) Kaheks või rohkemaks osaks jagatud trummidel tundub uss, selle seotus teiste motiividega ning ussitaolised siksak-ilustused toetavat Skanke-Jesseni hüpoteesi. Sellegipoolest on tõenäoline, et trummi tavakasutajale, kui ta eesmärgiks oli heita pilk tulevikusündmustele, oli ussil jumalate tahte näitaja roll. Sellele võimalusele viitavad ringi nimetused uss, konn. Ussi seosel ajaga (vrd trummidel Rudbeck K ja L) võib olla teatav tähtsus kaljumaalingute kontekstis.

Tõlkinud Liisa Vesik

\section{Tabel 1. Ussi ja siksaki motiivid Åsele-tüüpi trummidel}

Åsele-tüüpi trummid, kokku 47 trummi (44 kättesaadavad + 3 mitte kättesaadavad), millest ussi või siksaki kujutis esineb 30 trummil (28 kättesaadavad + 2 mitte kättesaadavad)

Tabel 1A

\begin{tabular}{|c|c|c|}
\hline Motiivi asukoht & kokku & ebakindel \\
\hline Päikese sümbolist vasakul & 28 & $1(\stackrel{*}{*})$ \\
\hline Päikese sümboli all & 1 & \\
\hline Päikese sümbolist paremal & $1(\stackrel{* 2}{)})$ & 1 \\
\hline Päikese sümboli lähedal & 12 & \\
\hline Päikese sümbolist eemal & 18 & \\
\hline
\end{tabular}

Tabel 1B

\begin{tabular}{|l|l|l|}
\hline \multicolumn{1}{|c|}{$\begin{array}{l}\text { Motiivid ussi võii siksaki kujutise } \\
\text { lähedal }\end{array}$} & kokku & Ebakindlad \\
\hline Saami küla/maja (kota/lager) & 17 & 2 \\
\hline $\begin{array}{l}\text { Ohverduskoht/püha mägi } \\
\text { (passe/passevarre) }\end{array}$ & 16 & 1 \\
\hline $\begin{array}{l}\text { Ohvriloom (Horagalles'ile) } \\
\text { põhjapõder/põhjapõdra kari/põhjapõdra } \\
\text { aedik }\end{array}$ & 13 & 10 \\
\hline \begin{tabular}{l} 
Mees/suusataja/kalamees \\
\hline
\end{tabular} & 8 & 1 \\
\hline
\end{tabular}




\begin{tabular}{|l|l|l|} 
Ait (njalla) & 6 & \\
\hline Kalavõrk/kalapaat/järv & 9 & 4 \\
\hline Mõni jumalus & 9 & 1 \\
\hline Shamaan/trumm & 6 & 3 \\
\hline $\begin{array}{l}\text { Shamaani põhjapõder (noiade } \\
\text { sarva)/muu shamaaniloom }\end{array}$ & 8 & 1 \\
\hline Karu & 5 & 2 \\
\hline $\begin{array}{l}\text { Kobras } \\
\begin{array}{l}\text { Allilm/teine ilm (Saivo-/Jabme-/Rota- } \\
\text { aimo) }\end{array}\end{array}$ & 5 & 2 \\
\hline Puu & $1(\underline{* 3})$ & 3 \\
\hline & &
\end{tabular}

1. Trumm 14, kujutis 18, tõlgendused:"Wasserlauf, Fischgewässer (? ev. Schlange)"

2. Trumm 36, kujutis 8. Defineerimata siksak

3. Trumm 36, kujutis 24. Tõlgendus: "Wachstumsymbole, Baumeister (?)".

\section{Tabel 2}

Tabel 2A. Kaheks või rohkemaks jagatud trummipead

\begin{tabular}{|c|c|c|c|c|c|c|c|c|c|c|c|c|c|c|c|}
\hline $\begin{array}{l}\text { Trummi } \\
\text { number }\end{array}$ & 43 & 47 & $\begin{array}{l}51 \\
(1 \\
)\end{array}$ & 61 & 62 & 63 & 69 & 70 & I & II & III & IV & $\mathbf{V}$ & Kokku & ebakindlad \\
\hline Osade arv & 3 & 2 & 2 & 2 & 2 & 2 & 4 & 3 & 2 & 7 & 3 & 2 & 2 & & \\
\hline $\begin{array}{l}\text { Motiivi } \\
\text { asukoht }\end{array}$ & & & & & & & & & & & & & & & \\
\hline $\begin{array}{l}\text { Ülemine } \\
\text { osa }\end{array}$ & & & & $\begin{array}{l}1 \\
(\underline{2} \\
)\end{array}$ & & & & & & & & & & 1 & \\
\hline $\begin{array}{l}\text { Keskmine } \\
\text { osa }\end{array}$ & & & & & & & 1 & 1 & & & 1 & & & 3 & \\
\hline $\begin{array}{l}\text { Alumine } \\
\text { osa }\end{array}$ & 1 & 1 & 1 & $\begin{array}{l}1 \\
(\underline{2} \\
)\end{array}$ & 1 & 1 & & 1 & 1 & 1 & 1 & 1 & 1 & 11 & 1 \\
\hline
\end{tabular}

1. Kujutis 22 siksakjoonega. Tõlgendus:"Fischgewässer, Bach".

2. Seal on palju siksakmotiive, uss on kujutis 13. 
Tabel 2B. Ussi või siksaki lähedal asuvad motiivid

\begin{tabular}{|c|c|c|c|c|c|c|c|c|c|c|c|c|c|c|c|}
\hline $\begin{array}{l}\text { Trummi } \\
\text { number }\end{array}$ & 43 & 47 & $\begin{array}{l}51 \\
(\underline{1} \\
)\end{array}$ & 61 & 62 & 63 & 69 & 70 & I & II & III & IV & $\mathbf{V}$ & Kokku & ebakindlad \\
\hline Päike & & & & & & & & 1 & & & $\begin{array}{l}1 \\
(\underline{3})\end{array}$ & $\begin{array}{l}1 \\
(\underline{4})\end{array}$ & $\begin{array}{l}1 \\
( \\
\frac{3}{)} \\
\end{array}$ & 4 & \\
\hline Kuu & & & & 1 & & & & 1 & & & & & & 2 & \\
\hline $\begin{array}{l}\text { Ohverduspaik/ } \\
\text { seit }\end{array}$ & 1 & & & & & & & & & & 1 & & & 2 & \\
\hline $\begin{array}{l}\text { Saami } \\
\text { küla/maja } \\
\text { (kota) }\end{array}$ & & 1 & & & & & & & & & 1 & & & 2 & \\
\hline $\begin{array}{l}\text { Allilm/teine } \\
\text { ilm }\end{array}$ & 1 & $1 ?$ & 1 & & 1 & 1 & & & $\begin{array}{l}1 \\
( \\
\frac{5}{5} \\
\end{array}$ & & 1 & $\begin{array}{l}1 \\
(\underline{5})\end{array}$ & 1 & 9 & 1 \\
\hline mõni jumalus & 1 & 1 & & & & 1 & 1 & & & $\begin{array}{l}1 \\
(\underline{6} \\
)\end{array}$ & 1 & 1 & 1 & 8 & \\
\hline Shamaan & & & & & $1 ?$ & & & & & & 1 & & & 2 & 1 \\
\hline $\begin{array}{l}\text { Inimene/jahim } \\
\text { ees }\end{array}$ & & & & & $1 ?$ & & 1 & & & & & & & 2 & 1 \\
\hline $\begin{array}{l}\text { Shamaani } \\
\text { loom }\end{array}$ & & & & & & & & & & & & & & - & \\
\hline $\begin{array}{l}\text { mõni muu } \\
\text { loom }\end{array}$ & & & & 1 & & 1 & 1 & & 1 & 1 & 1 & 1 & 1 & 8 & \\
\hline $\begin{array}{l}\text { Paat } \\
\text { (Ringhorna) }\end{array}$ & & & & & & & & & & & 1 & & 1 & 2 & \\
\hline Ait (njalla) & & & 1 & & & & & & & & & & & 1 & \\
\hline Järv & & & 1 & & & & & & & & & & & 1 & \\
\hline
\end{tabular}

3. Päike talvel.

4. Kaks päikest, talvine ja tavaline.

5. Oridaani meri

6. Tod (döden)

$\mathrm{I}=$ Sceffeus, Trommel A (Rudbeck A)

II = Sceffeus, Trommel G

III = Rudbeck, Trommel G

IV = Rudbeck, Trommel K

$\mathrm{V}=$ Rudbeck, Trommel L 


\section{Allikad ja avaldamata kirjandus}

\section{Helsinki}

MV - Museovirasto

Luho, V. 1964. Kirkkonummi, Österby, Juusjärvi. Kertomus kalliomaalausten tutkimisesta. Miettinen, M. \& Miettinen T. 1978. Copies of the rock paintings of Sarakallio.

Tartu

EAGA - Eesti Muinastaide Selts. Äänisjärve idakaldal 1986-1988 tehtud koopiad.

Turu

TY - Turun Yliopisto. Eelajaloo õppetool.

Miettinen, T. [1987]. Kalliotaitteemme tulkintaongelmista. Turu kaljutaide sümpoosionil peetud ettekande tekst. 28-29. september 1987.

\section{Kirjandus}

Andelin, A. 1858. Kertomus Utsjoen pitäjästä. Suomi 1858. Helsingfors.

Aspelin, J. R. 1877. Muinaisjäännöksiä Suomen suvun asumus-aloilla. Helsinki.

Autio, E. 1981. Karjalan kalliopiirrokset. Keuruu.

Autio, E. 1984. Hirvi ja käärme Uikujoen kalliosta. Kotiseutu. Helsinki.

Burenhult, G. 1979. Hällbilder från sten- och bronsålder i Norden. Malmö Museum. Malmö.

Clark, R., Rundle T. 1960. Myth and symbol in Ancient Egypt. London.

Cooper, J. C. 1983. Symboler. Helsingborg.

Finnish folk poetry: Epic. 1977. Ed. and transl. by M. Kuusi. Helsinki.

Formozov, A. A. 1966. Pamjatniki pervobõtnogo iskusstva na territorii SSSR. Moskva.

Formozov, A. A. 1987. Naskalnõje izobrazhenija i ihh izutshenije. Moskva.

Frolov, B. A. 1974. Tshisla v grafike neolita. Novosibirsk.

Gjessing, G. 1978. Rock-pictures in Northern Fenno-Scandinavia and their eastern affinities. Acts of the international symposium on rock art. Ed. by S. Marstrander. (Instituttet for sammelignende kulturforskning A, 29.) Oslo.

Gurina, N. N. 1956. Olenoostrovskii Mogilvnik. Materialõ i issledovanija po arheologii SSSR. Moskva.

Gurina, N. N. 1980. Naskalnõje rissunki Kolskogo poluostrova i sopredelnõhh oblastei. Zveri $i$ kamni. Novosibirsk.

Haavio, M. 1939. Huomioita suomalaisen kansanperinteen kartoittamisesta. Virittäjä 43.

Helsinki.

Hallström, G. 1960. Monumental art of Northern Sweden from the Stone Age. Stockholm.

Helskog, K. 1985. Selective depictions. A study of 3,500 years of rock carvings from Arctic

Norway and their relationship to the Sami drums. Archaeology as a long term history.

Cambridge.

Helskog, K. 1988. Helleristningene i Alta. Alta Museum. Alta.

Holmberg, U. 1914. Permalaisten uskonto. Porvoo.

Itkonen, T. I. 1948. Suomen lappaiset vuoteen 1945 2. Porvoo.

Ivanov, S. V. 1954. Materialõ po izobrazitelnomu iskusstvu narodov Sibiri XIX-natshala XX v.

Moskva.

James, E. O. 1959. The cult of the Mother-Goddess. An archaeological and documentary study.

London.

Levy, G. R. 1946. The Gate Horn. A study of the religious conceptions of the Stone Age, and their influence upon European thought. New York. 
Linevski, A. M. 1939. Petroglifõ Karelii. Tsh. I. Petrozavodsk.

Luho, V. 1962. Klippmålningen vid Juusjärvi. Finsk Museum 69. Helsingfors.

MacCana, P. 1983. Celtic mythology. London.

Manker, E. 1938. Die lappische Zaubertrommel 1. (Acta Lapponica 1.) Stockholm.

Manker, E. 1950. Die lappische Zaubertrommel 2. (Acta Lapponica 6.) Stockholm.

Meri, L. 1983. Hopeanvalkea. [Tõlkinud] E. Lille. Jyväskylä.

Miettinen, T. 1982. Kuvat kalliossamme / Pictures on the Finnish rocks. Helsinki.

Ojonen, S. 1973. Hällmålningarna vid sjöarna Kotojärvi och Märkjärvi i Iitti. Finsk Museum

80. Helsingfors.

Okladnikov, A. P. 1966. Petroglifõ Angarõ. Moskva-Leningrad.

Okladnikov, A. P. \& Martõnov, A. I. 1972. Sokrovishtsha tomskihh pissanits. Moskva.

Okladnikov, A. P. \& Petrin, V. T. 1983. Paleolititsheskije rissunki Ignatjevskoi peshtsherõ na Juzhnom Urale. Plastika i rissunki drevnihh kultur. Novosibirsk.

Raudonikas, V. I. 1936-38. Naskalnõje izobrazhenija Onezhkogo ozera i Belogo morja. I-II.

Moskva-Leningrad.

Ruuttu, M. 1929. Eläinmaailmaa kannakselaisten uskomuksissa. Virttäjä 33. Helsinki.

Ränk, G. 1949. Kysymys Lapin Madderakasta ja hänen tyttärinesä alkuperästä.

Kalevalaseuran vuosikirja 29. Porvoo.

Salo, U. 1984. Pyyntikulttuurista maanviljelyyn. Sukopolvien perintö 1. [Toimetanud] E.

Kirkinen \& T. Hakamäki \& M. Linkola. Helsinki.

Sarvas, P. \& Taavitsainen, J.-P. 1975. Käköveden kalliomaalaukset. Kotiseutu. Helsinki.

Savvatejev, J. A. 1983. Naskalnõje rissunki Karelii. Petrozavodsk.

Schlette, G. 1976. Kelten zwischen Alesia und Pergamon. Leibzig.

Siikala, A.-L. 1980. Mitä kalliomaalauksemme kertovat Suomen kampa-keraamisen väestön uskomusmaailmasta. Suomen Antropologi 1980, 4. Helsinki.

Sommarström, B. 1987. Ethnoastronomical perspectives on Saami religion. Saami religion.

Ed. by T. Ahlbäck. (Scripta Instituti Donnerian Aboensis 12.) Åbo.

Spitsõn, A. A. 1906. Shamanskije izobrazhenia. ZORSA. t. VIII, võp. 1. Moskva

Studzitskaja, S. V. 1987. Izobrazhenije tsheloveka v iskusstve drevnego nasselenija Uralo-

Zapadnosibirskogo regiona. Antropomorfnõje izobrazhenija. Pervobõtnoje iskusstvo.

Novosibirsk.

Taavitsainen, J.-P. 1979. Suomussalmen Värikallio. Kotiseutu. Helsinki.

Tallqvist, K. 1943. Eläinrata. (Suomen itämaisen seuran kansantajuisia julkaisuja 10.

Suomen tiedettä 2.) Helsinki.

Tsharnoluski, V. V. 1965. Legenda ob olene-tsheloveke. Moskva.

Tshernetsov, V. N. 1953. Bronza Ust-poluiskogo vremeni. Dreunjaja istorija Nizhnego Priobja.

Moskva.

Tshernetsov, V. N. 1964. Naskalnõje izobrazhenija Urala I. Moskva.

Tshernetsov, V. N. 1971. Naskalnõje izobrazhenija Urala II. Moskva.

Tynni, A. 1980. Johdanto. Eddan sankarirunot. [Tõlkinud ja toimetanud] A. Tynni. Porvoo.

Waronen, M. 1895. Vainajain palvelus muinaisilla suomalaisilla. Helsinki.

\section{Kommentaarid:}

1. Kuna see kujutis on (nagu teisedki) jumalate märk, ei kujuta see trummi omanikku, vrd joonis 45 .

2. Vaevalt, et kujutatakse lindu, vrd joonis 20. Vt ka märke trummil 5: 11, $42: 1$ ja 69: 2. 